Research Article

\title{
Assessment of Patient's Satisfaction and Associated Factors regarding Postoperative Pain Management at the University of Gondar Compressive Specialized Hospital, Northwest Ethiopia
}

\author{
Yosef Belay Bizuneh $(\mathbb{D}$, Girmay Fitiwi Lema $(\mathbb{D}$, Demeke Yilkal Fentie $\mathbb{D}$, \\ Yophtahe Woldegerima Berhe $\mathbb{D}$, and Henos Enyew Ashagrie $\mathbb{1}$
}

Department of Anesthesia, College of Medicine and Health Sciences, University of Gondar, Gondar, Ethiopia

Correspondence should be addressed to Yosef Belay Bizuneh; phanuelyosef@gmail.com

Received 18 September 2020; Revised 19 October 2020; Accepted 29 October 2020; Published 12 November 2020

Academic Editor: Giustino Varrassi

Copyright (C) 2020 Yosef Belay Bizuneh et al. This is an open access article distributed under the Creative Commons Attribution License, which permits unrestricted use, distribution, and reproduction in any medium, provided the original work is properly cited.

\begin{abstract}
Objective. We aimed to assess the level of patient's satisfaction and associated factors regarding postoperative pain management. Methods. An institution-based cross-sectional study was conducted from April to May 2018 at the University of Gondar, and comprehensive specialized hospital data were collected through semistructured questionnaire and chart review. Level of satisfaction was measured using five-point Likert scale. Statistical analysis was done using SPSS software version 23. Both bivariable and multivariable logistic regression analyses were done. Variables of $P$ value $\leq 0.2$ in the bivariable analysis were a candidate for multivariable logistic regression. A $P$ value $\leq 0.05$ was considered as significantly associated with patient's level of satisfaction at 95\% CI. Results. A total of 418 patients were included in this study with a response rate of $98.58 \%$. The overall proportion of patients who were satisfied with pain management services was 72.2\% (95\% CI: 67.7-76.6). ASA1 (AOR =3.55: 95\% $\mathrm{CI}=1.20-10.55)$ and $\mathrm{ASA} 2$ patients $(\mathrm{AOR}=3.72: 95 \% \mathrm{CI}=1.04-13.28)$, absence of postoperative pain $(\mathrm{AOR}=1.86: 95 \%$ $\mathrm{CI}=1.02-3.39)$, peripheral nerve block done $(\mathrm{AOR}=9.14: 95 \% \mathrm{CI}=3.9320 .86)$, received analgesic before request $(\mathrm{AOR}=6.90$ : $95 \% \mathrm{CI}=3.72-12.83)$, and received systemic analgesics ( $\mathrm{AOR}=6.10: 95 \% \mathrm{CI}=1.17-33.91)$ were significantly associated with the level of satisfaction. Conclusion. The level of patient satisfaction with postoperative pain management was considerably low. Hence, it is vital to implement time-interval pain assessment method during the first 24 hours of postoperative period and treat accordingly based on the WHO pain ladder. Moreover, we suggested that all patients who underwent major surgery should receive peripheral nerve block as part of multimodal analgesia to decrease the incidence and severity of post op pain.
\end{abstract}

\section{Background}

Globally, postoperative pain is one of the major concerns in surgical patients and many studies have been done through different methods to assess patient satisfaction with postoperative pain management and associated factors [1-3].

Satisfaction is a general psychological condition that results from emotional surrounding expectations coupled with the prior feeling of consumers toward the consumption experience [4]. Patient's satisfaction in pain management is one of the variables that affect the outcomes of health care services, but it could be difficult to achieve by a single specific intervention [5, 6]. Previously, traditional lack of complications and vital sign was used as a measurement of clinical success. However, recently, patient-reported outcome measures or patient satisfaction are the most relevant criteria of clinical success [7].

Studies suggested that pain management can be affected by multiple factors such as gender, age, preoperative expectations, information given prior to surgery, ASA status, preoperative pain medication, type of anesthesia, type and duration of surgery, communication of staffs with patient, 
and experience of pain relief [8-11]. Patients' level of satisfaction could be increased via providing preoperative information related to postoperative pain, preoperative education, and nonpharmacological treatment $[12,13]$.

Untreated postoperative pain may have an effect in the clinical and psychological status of the patients. In addition, it creates a burden to health institutions by increasing costs and prolonging hospital stay. In addition, untreated acute postoperative pain may change to chronic pain with sequelae of decreased quality of life with different clinical sequels [14-18].

Despite different methods of postoperative pain control have been provided to surgical patients, there had been lack of evidence that examined patients' satisfaction with the quality of postoperative pain management in the study area. Therefore, we aimed to assess the level of patient's satisfaction and identifying factor that could affect postoperative pain management.

\section{Methods}

2.1. Study Design, Area, and Period. Institution-based crosssectional study was conducted from April to May 2018 at the University of Gondar Comprehensive Specialized Hospital, northwest Ethiopia. The University of Gondar Comprehensive Specialized Hospital is a referral and teaching hospital which is found in Gondar town, about $738 \mathrm{~km}$ northwest from Addis Ababa, capital of Ethiopia, and $230 \mathrm{~km}$ from Ethiopia-Sudan boarder. The hospital is estimated to serve over 5 million people around the area and according to the annual report of the hospital, more than six thousand patients were operated on per annum.

\subsection{Sample Size Determination and Sampling Procedure.} Sample size was calculated using a single population proportion formula. In a previous study done in Jimma University Specialized Hospital, it was shown that satisfaction rate was $50 \%, 5 \%$ of accepted difference, and CI of $95 \%$ :

$$
\mathbf{n}=\frac{(\mathrm{Z} \boldsymbol{\alpha} / \mathbf{2})^{2} \mathbf{p}(\mathbf{1}-\mathbf{p})}{\mathbf{W}^{2}}
$$

Assumptions $\mathbf{n}=$ is the required sample size, $\mathbf{Z}=$ critical value for normal distribution at $95 \%$ confidence level (1.96), $\mathbf{W}=0.05 \quad(5 \%$ margin of error), $\boldsymbol{\alpha}=$ the level of significance $=$ best estimate of the population proportion, and $10 \%$ of nonresponse rate was added. Therefore, based on the abovementioned assumptions, 424 participants were enrolled in this study. All consecutive surgical patients were included until the calculated sample size was reached.

2.3. Data Collection Procedure. Data were collected through patients' chart review, interview, and five-point Likert scale. Questionnaires including five-point Likert scale were translated to local language (Amharic language) and pretest was done on 43 patients (10\% of the estimated sample size) and amendment was done before the actual data collection.

Data was collected at 24 hours after operation. Two junior anesthetists were involved in data collection after receiving training and supervised by the principal investigator. The level of patient's satisfaction was measured using five-point Likert scale $((1=$ very dissatisfied, $2=$ dissatisfied, $3=$ neutral, $4=$ satisfied, and $5=$ very satisfied) and checklist. The reliability coefficient (Cronbach $s, s^{-}$alpha) test of this instrument was 0.97 . The questionnaire was modified from the American Pain Society satisfaction survey, American Pain Society patient-outcomes questionnaires-modified [18-20], and the Department of Anesthesiology and Intensive Care, Helsinki University Hospital [11].

\subsection{Study Variables}

2.4.1. Dependent Variables. Level of patient's satisfaction expressed through 5-point Likert scale. Patients' level of satisfaction with postoperative pain management was based on the demarcation threshold formula [total highest score total - lowest score]/2] + (total lowest score) [21-25]. Patient who scored less than 79.5 points out of 130 was considered as dissatisfied whereas 79.5 and above was considered as satisfied.

\subsubsection{Independent Variables}

(1) Sociodemographic Factors. Sex, age, BMI, and level of education.

(2) Preoperative Factors. Previous surgical history, preoperative pain, treatment and previous side effects of pain medication, preoperative information of postoperative pain management, and disease status.

(3) Surgical Related Factors. Body site of surgery, type of surgery, type of anesthesia and analgesia, duration of surgery, surgeon, and intra- and postoperative pain.

2.5. Data Processing and Analysis. Data clean-up and crosschecking were done before analysis. The coded data were entered to Epi Info software version 7 and exported to SPSS version 23. Bivariate and multivariate logistic regression analyses were used to control the possible confounding factors and to identify factors associated with patient's satisfaction. The cut-off point for statistical significance was $<0.2$ and 0.05 for bivariate and multivariate logistic regression analyses, respectively. The relationship of nominal data with satisfaction was analyzed by using cross tabulations. Categorical data were presented as numbers and frequencies (percentages). Patient's satisfaction through five-point Likert scale was dichotomized in to satisfied and dissatisfied groups based on demarcation threshold formula.

\section{Results}

3.1. Sociodemographic and Clinical Characteristics of the Study Participants. A total of 418 patients with a response rate of 98.58\% were enrolled in this study. Six patients were excluded from analysis for incomplete data. Two-thirds of the study subjects, 279 (66.7\%), were females. Most of the 
respondents, $311(74.4 \%)$, were in the age group of 18-39 years and the mean age \pm SD was $33.5 \pm 13.2$ years and the mean \pm SD of BMI was $22.2+3.0 \mathrm{~kg} / \mathrm{m}^{2}$. The majority of the study participants, $64.4 \%, 87.1 \%$, and $55 \%$, underwent abdominal procedure, major surgery, and emergency surgery, respectively. More than fifty percent (54.1\%), 45.9\%, of patients were operated on under general anesthesia and $54.1 \%$ were operated on under spinal anesthesia (Table 1 ).

3.2. Level of Patient's Satisfaction in Postoperative Pain Management with Subscales and Overall. The overall of patients who were satisfied with pain management service was $72.2 \%$ (95\% CI: 67.7-76.6). The highest satisfaction score was with communication and the way of response to reports of pain $(76.6 \%)$ whereas the lowest score was with preoperative information and general care (Figure 1).

\subsection{Factors Associated with Patient's Satisfaction with Post-} operative Pain Management. Multivariate analysis showed that ASA status, postoperative pain, nerve block, receive analgesics, and analgesics before request were the significant factors associated with patient satisfaction in postoperative pain management (Table 2).

\section{Discussion}

Previous studies showed that the level of patient satisfaction was not associated with postoperative pain severity, since the majority of the patients were considered satisfied, even though they had moderate-to-severe pain. In contrary, other studies showed that satisfaction was associated with postoperative pain management [26-29].

In the current study, the overall proportion of patients who were satisfied with pain management services was 72.2\% (95\% CI: 67.7-76.6). This finding was low compared with other studies $[3,8,9,11,14,26,30-33]$. This could be due to the good caring attitude of health care professional, high rate of preoperative pain education, presence of good communication, and providing frequent education on painrelated issues for the ward nurses, especially focusing on the frequent measurement of pain assessment $[11,34,35]$. In addition, nonpharmacological pain management methods were implemented but not in the study area [10]. However, our finding was high compared with the recent study of Jimma (Ethiopia), which showed that the overall proportion of patients satisfaction was 50\% [36]. This discrepancy could be because the peripheral nerve block was a common method of pain management in the study area while this method was not mentioned in that study.

In the current study, we found that disease status has an association with the level of satisfaction, ASA1 patients were 3.5 times more likely to be satisfied compared with ASA3 and ASA4 patients $(\mathrm{AOR}=3.55(1.20-10.55))$ and ASA2 patients were 3.7 times more likely to be satisfied compared with ASA3 and ASA4 patients (AOR $=3.72,95 \%$ $\mathrm{CI}=1.04-13.28)$. A study conducted in Australian patients showed that ASA3 and above were associated with patients' dissatisfaction in postoperative pain management survival in
TABLE 1: Sociodemographic and clinical characteristics of patients underwent surgery under anesthesia at the University of Gondar comprehensive specialized hospital, northwest Ethiopia, 2018 $(N=418)$.

\begin{tabular}{|c|c|c|c|}
\hline Variables & & $\begin{array}{l}\text { Frequency } \\
(n)\end{array}$ & $\begin{array}{c}\text { Percentages } \\
(\%)\end{array}$ \\
\hline \multirow{2}{*}{ Gender } & Male & 139 & 33.3 \\
\hline & Female & 279 & 66.7 \\
\hline \multirow{3}{*}{ Age (years) } & $18-39$ & 311 & 74.4 \\
\hline & $40-55$ & 73 & 17.5 \\
\hline & $>55$ & 34 & 8.1 \\
\hline \multirow{4}{*}{ BMI } & Under weight & 29 & 6.9 \\
\hline & Normal & 325 & 77.8 \\
\hline & Over weight & 53 & 12.7 \\
\hline & Obese & 11 & 2.6 \\
\hline \multirow{5}{*}{ Education } & $\begin{array}{l}\text { Unable to read and } \\
\text { write }\end{array}$ & 216 & 51.7 \\
\hline & $\begin{array}{c}\text { Able to read and } \\
\text { write }\end{array}$ & 8 & 1.9 \\
\hline & Primary school & 43 & 10.3 \\
\hline & High school & 83 & 19.9 \\
\hline & College/university & 68 & 16.3 \\
\hline \multirow{3}{*}{ ASA status } & ASA1 & 311 & 74.4 \\
\hline & ASA2 & 69 & 16.5 \\
\hline & ASA3 and ASA4 & 38 & 9.1 \\
\hline \multirow{6}{*}{$\begin{array}{l}\text { Body site of } \\
\text { surgery }\end{array}$} & Limbs & 47 & 11.2 \\
\hline & Head and neck & 52 & 12.4 \\
\hline & Thoracic & 8 & 1.2 \\
\hline & Abdomen & 269 & 64.4 \\
\hline & Spine & 4 & 1.00 \\
\hline & Genitourinary & 38 & 9.1 \\
\hline \multirow{4}{*}{$\begin{array}{l}\text { Types of } \\
\text { surgery }\end{array}$} & Elective & 188 & 45 \\
\hline & Emergency & 230 & 55 \\
\hline & Major & 364 & 87.1 \\
\hline & Minor & 54 & 12.9 \\
\hline \multirow{2}{*}{$\begin{array}{l}\text { Type of } \\
\text { anesthesia }\end{array}$} & GA & 192 & 45.9 \\
\hline & SA & 226 & 54.1 \\
\hline
\end{tabular}

Data were expressed in number and percentage. GA: general anesthesia. SA: spinal anesthesia.

univariate odds ratio analysis. However, after adjustment, ASA status was no longer in associated with patients dissatisfaction [33].

Patients who received a postoperative regional analgesic technique generally had lower pain scores and a higher level of satisfaction $[6,37-41]$. In the present study, $95.7 \%$ of patients were satisfied with postoperative nerve block, which was 9 times more likely to be satisfied compared with patients without nerve block $(\mathrm{AOR}=9.14, \quad 95 \%$ $\mathrm{CI}=3.93-20.86)$. This showed that our study had similar finding with other studies $[6,37,38,40]$. This is because of nerve block has superior postoperative analgesia, which may result in higher levels of patient's satisfaction [38].

From 418 patients, 15 (3.6\%) had not received analgesics; among them, only $5(33.3 \%)$ patients were satisfied whereas $10(66.6 \%)$ patients were dissatisfied. When compared with patients who had received analgesic versus patients who had not received analgesics, patients who had received analgesic were 6 times more likely to be satisfied $(A O R=6.1: 95 \%$ $\mathrm{CI}=1.17-33.91)$. Furthermore, in the other studies, it was shown that patients who had received analgesics 


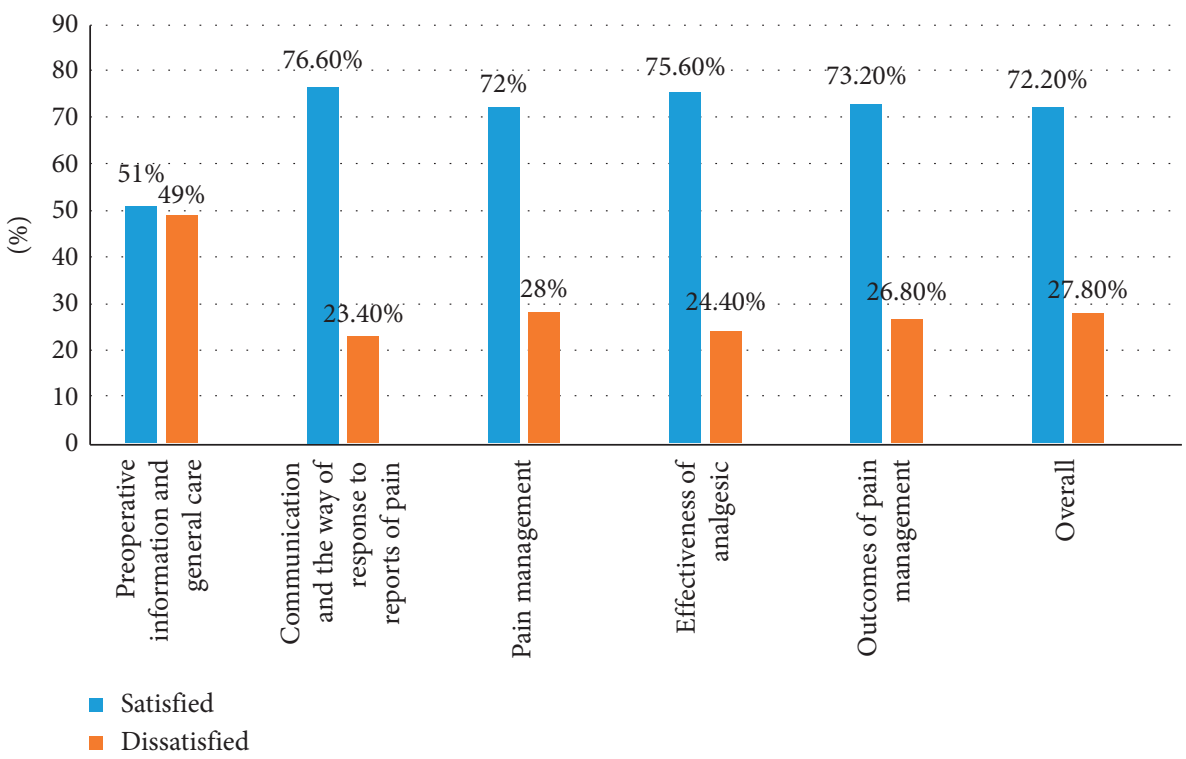

FIgURE 1: Level of patients' satisfaction with subscales and overall in postoperative pain management at the University of Gondar comprehensive specialized hospital, northwest Ethiopia, $2018(N=418)$.

TABLE 2: As assessed $24 \mathrm{~h}$ after surgery, bivariate and multivariate logistic regression analyses results, patients experiences in perioperative time for satisfaction of postoperative pain management, assessed at 24 hours following surgery in the University of Gondar compressive specialized hospital, northwest Ethiopia, $2018(N=418)$.

\begin{tabular}{|c|c|c|c|c|c|}
\hline \multirow{2}{*}{ Variables } & & \multicolumn{2}{|c|}{ Level of satisfaction } & \multicolumn{2}{|c|}{ Odds ratio with $95 \% \mathrm{CI}$} \\
\hline & & Satisfied & Dissatisfied & Corollary $(95 \% \mathrm{CI})$ & AOR (95\% CI) \\
\hline \multirow{3}{*}{ Age (years) } & $18-39$ & $218(70.1)$ & $93(29.9)$ & $1^{\mathrm{a}}$ & 1 \\
\hline & $40-55$ & $60(82.2)$ & $13(17.8)$ & $1.97(1.03,3.76)^{*}$ & $2.0(0.79,5.19)$ \\
\hline & $>55$ & $24(70.6)$ & $10(29.4)$ & $1.02(0.47,2.22)$ & $0.68(0.22,2.03)$ \\
\hline \multirow{4}{*}{ Body mass index } & Normal weight & $236(72.6)$ & $89(27.4)$ & $1^{\mathrm{a}}$ & 1 \\
\hline & Over weight & $44(83)$ & $9(17)$ & $1.84(0.86,3.930$ & $1.47(0.56,3.87)$ \\
\hline & Obese & $6(54.5)$ & $5(45.5)$ & $0.45(0.14,1.52)$ & $0.73(0.13,4.15)$ \\
\hline & Under weight & $16(55.2)$ & $13(44.8)$ & $0.46(0.22,1.00)$ & $0.59(0.17,1.44$ \\
\hline \multirow{3}{*}{ ASA } & ASA1 & $222(71.4)$ & $89(28.6)$ & $1.81(0.91,3.61)$ & $3.55(1.20,10.55)^{*}$ \\
\hline & ASA2 & $58(84.1)$ & $11(15.9)$ & $3.84(1.54,9.54)^{1}$ & $3.72(1.04,13.28)^{*}$ \\
\hline & ASA 3 and ASA4 & $22(57.9)$ & $16(42.1)$ & $1^{\mathrm{a}}$ & $1^{\mathrm{b}}$ \\
\hline \multirow{6}{*}{ Body site of surgery } & Limbs & $32(68.1)$ & $15(31.9)$ & $1^{\mathrm{a}}$ & 1 \\
\hline & Head and neck & $39(75)$ & $13(25)$ & $1.41(0.59,3.38)$ & $1.06(0.28,3.84)$ \\
\hline & Thoracic & $7(87.5)$ & $1(12.5)$ & $3.28(0.37,29.12)$ & $3.24(0.23,46.39)$ \\
\hline & Abdominal & $189(70.3)$ & $80(29.7)$ & $1.12(0.57,2.16)$ & $0.66(0.24,1.78)$ \\
\hline & Spine & $4(100)$ & $0(0)$ & & \\
\hline & Genitourinary & $31(81.6)$ & $7(18.4)$ & $2.08(0.75,5.78)$ & $3.37(0.68,16.66)$ \\
\hline \multirow{2}{*}{ Type of surgery } & Elective & $159(84.6)$ & $29(15.4)$ & $3.34(2.07,5.38)^{* * *}$ & $0.41(0.15,1.10)$ \\
\hline & Emergency & $143(62.2)$ & $87(37.8)$ & $1^{\mathrm{a}}$ & 1 \\
\hline \multirow{2}{*}{ PONB } & Yes & $154(95.7)$ & $7(4.3)$ & $16.20(7.30,35.95)^{* *}$ & $9.14(3.93,20.86)^{* *}$ \\
\hline & No & $148(57.6)$ & $109(42.4)$ & $1^{\mathrm{a}}$ & $1^{\mathrm{b}}$ \\
\hline \multirow{2}{*}{ Analgesics } & Yes & $297(73.7)$ & $106(26.3)$ & $5.6(1.87,16.77)^{*}$ & $6.10(1.17,33.91)^{*}$ \\
\hline & No & $5(33.3)$ & $10(66.7)$ & $1^{\mathrm{a}}$ & $1^{\mathrm{b}}$ \\
\hline \multirow{2}{*}{ Information of POPM } & Yes & $38(61.3)$ & $24(38.7)$ & $0.55(0.31,0.97)^{*}$ & $0.49(0.22,1.08)$ \\
\hline & No & $264(74.2)$ & $92(25.8)$ & $1^{a}$ & 1 \\
\hline \multirow{2}{*}{ Intraoperative pain } & Yes & $42(58.3)$ & $30(41.7)$ & $1^{\mathrm{a}}$ & 1 \\
\hline & No & $260(75.1)$ & $86(24.9)$ & $2.16(1.27,3.66)^{*}$ & $1.31(0.61,2.85)$ \\
\hline \multirow{2}{*}{ Postoperative pain } & Yes & $80(57.3)$ & $69(46.3)$ & $1^{\mathrm{a}}$ & $1^{\mathrm{b}}$ \\
\hline & No & $222(82.5)$ & $47(17.5)$ & $4.07(2.6,6.48)^{* *}$ & $1.86(1.02,3.39)^{*}$ \\
\hline \multirow{2}{*}{ Analgesic before request } & Yes & $260(86.4)$ & $41(13.6)$ & $11.32(6.86,18.69)^{* *}$ & $6.90(3.72,12.83)^{* *}$ \\
\hline & No & $42(35.9)$ & $75(64.1)$ & $1^{a}$ & $1^{\mathrm{b}}$ \\
\hline \multirow{2}{*}{ Analgesic when need it } & Yes & $56(72.7)$ & $21(27.3)$ & $1.03(0.59,1.79)$ & \\
\hline & No & $246(72.1)$ & $95(27.9)$ & 1 & \\
\hline
\end{tabular}

${ }^{*}=P$ value $<0.05,{ }^{* *}=P<0.001,{ }^{\mathrm{a}}=$ significant from bivariate logistic regression model, and ${ }^{\mathrm{b}}=$ significant from multivariate logistic regression model. $\mathrm{PRNB}:$ peripheral nerve block. POPM: postoperative pain management. 
postoperatively were highly satisfied compared with nontreated patients $[20,42]$.

In the current study, 149 (35.6\%) patients had pain immediately after the operation. Those patients were 1.8 times less satisfied when compared with those who did not have pain immediately after the operation (AOR $=1.86$ : $95 \%$ $\mathrm{CI}=1.02-3.39$ ). Several studies conclude that patients' satisfaction with postoperative pain management was associated with the patients' actual pain experience $[9,19,27,34,43]$, and our finding was in accordance with the abovementioned literatures.

Another factor associated with patient satisfaction in postoperative pain management was using analgesic before request. Patients who received analgesics before request were 6.9 times more likely to be satisfied compared with those patients who had not received analgesics before request or totally did not receive analgesic ( $\mathrm{AOR}=6.90: 95 \% \mathrm{CI}=3.72-12.83)$. This finding is also in line with the other study and could be the association between pain management and patient's satisfaction [44].

\section{Conclusions}

The overall level of patient's satisfaction with postoperative pain management was considerably low as compared with other studies. ASA status, presence of pain immediately after operation, peripheral nerve block, administration of systemic analgesics, and analgesic before request were significant determinant factors for patients' level of satisfaction. Hence, it is vital to implement time-interval pain assessment method during the first 24 hours of postoperative period and treat accordingly based on the WHO pain ladder. Moreover, we suggested that all patients who underwent major surgery should receive peripheral nerve block as part of multimodal analgesia to decrease the incidence and severity of post op pain.

5.1. Limitation of the Study. Dichotomized Likert data leads to loss of information and the space between each choice cannot possibly be equidistant. The study did not include patients discharged before 24 hours, and after 24 hours, the level of satisfaction was not assessed.

\section{Abbreviations}

ASA: American Society of Anesthesiologists

SPSS: Statistical Package for Social Sciences

BMI: Body mass index

SD: $\quad$ Standard deviation

GA: General anesthesia

CI: Confidence interval

COR: Crude odds ratio

AOR: Adjusted odds ratio

POPM: Postoperative pain management

PONB: Postoperative nerve block.

\section{Data Availability}

All data generated or analyzed during this study are included in this published article.

\section{Ethical Approval}

Ethical clearance was obtained from the ethical review board of the School of Medicine, College of Medicine and Health Sciences, University of Gondar.

\section{Consent}

Written informed consent was obtained from each study participant after clear explanation of what they would have to do and take part in the study. Anyone not willing to participate in the study was informed that they have the full right not to participate or stop at any time and those who were not voluntary were excluded. Confidentiality was guaranteed by keeping the secrecy of personal identification, keeping completed questionnaires and checklist results in well-secured areas.

\section{Conflicts of Interest}

The authors declare that they have no conflicts of interest regarding the publication of this paper.

\section{Authors' Contributions}

YB conceived and designed the study, supervised the data collection, and performed the data analysis, interpretation of the result, and drafting of the manuscript. DY, GF, YW, and HE participated in designing the study, data analysis, data interpretation, and editing the manuscript. All authors read and approved the final manuscript.

\section{Acknowledgments}

The authors' deepest gratitude goes to the University of Gondar, College of Medicine and Health Sciences, for helping them to conduct this research. The authors also appreciate their data collectors for their enthusiastic and energetic participation in the process of data gathering. Finally, the authors extend their gratitude to the study participants who spent their precious time responding to their questionnaires.

\section{References}

[1] M. Polanco-Garcia, J. Garcia-Lopez, N. Fabregas, W. Meissner, and M. M. Puig, "Postoperative pain management in Spanish hospitals. A cohort study using the PAINOUT registry," The Journal of Pain, vol. 18, no. 10, pp. 1237-1252, 2017.

[2] T. G. Weiser, S. E. Regenbogen, K. D. Thompson et al., "An estimation of the global volume of surgery: a modelling strategy based on available data," The Lancet, vol. 372, no. 9633 , pp. 139-144, 2008.

[3] A. Teunkens, K. Vanhaecht, K. Vermeulen et al., "Measuring satisfaction and anesthesia related outcomes in a surgical day care centre: a three-year single-centre observational study," Journal of Clinical Anesthesia, vol. 43, pp. 15-23, 2017, PubMed PMID: 28964960. Epub 2017/10/02. eng.

[4] S. L. Beck, G. L. Towsley, P. H. Berry, K. Lindau, R. B. Field, and S. Jensen, "Core aspects of satisfaction with pain 
management: cancer patients' perspectives," Journal of Pain and Symptom Management, vol. 39, no. 1, pp. 100-115, 2010.

[5] D. Tong, F. Chung, and D. Wong, "Predictive factors in global and anesthesia satisfaction in ambulatory surgical patients," Anesthesiology, vol. 87, no. 4, pp. 856-864, 1997.

[6] C. Wu, M. Naqibuddin, and L. A. Fleisher, "Measurement of patient satisfaction as an outcome of regional anesthesia and analgesia: a systematic review," Regional Anesthesia and Pain Medicine, vol. 26, no. 3, pp. 196-208, 2001.

[7] D. Hamilton, J. V. Lane, P. Gaston, J. Patton, D. Macdonald, and A. Simpson, "What determines patient satisfaction with surgery? A prospective cohort study of 4709 patients following total joint replacement," BMJ Open, vol. 3, no. 4, Article ID e002525, 2013.

[8] M. Sjöling, G. Nordahl, N. Olofsson, and K. Asplund, "The impact of preoperative information on state anxiety, postoperative pain and satisfaction with pain management," Patient Education and Counseling, vol. 51, no. 2, pp. 169-176, 2003, PubMed PMID: 14572947. Epub 2003/10/24. eng.

[9] I. Svensson, B. Sjöström, and H. Haljamäe, "Influence of expectations and actual pain experiences on satisfaction with postoperative pain management," European Journal of Pain, vol. 5, no. 2, pp. 125-133, 2001, PubMed PMID: 11465978. Epub 2001/07/24. eng.

[10] J. Miller, A. Dunion, N. Dunn et al., "Effect of a brief massage on pain, anxiety, and satisfaction with pain management in postoperative orthopaedic patients," Orthopaedic Nursing, vol. 34, no. 4, pp. 227-234, 2015, PubMed PMID: 26213879. Epub 2015/07/28. eng.

[11] L. Niemi-Murola, R. Pöyhiä, K. Onkinen, B. Rhen, A. Mäkelä, and T. T. Niemi, "Patient satisfaction with postoperative pain management-effect of preoperative factors," Pain Management Nursing, vol. 8, no. 3, pp. 122-129, 2007, PubMed PMID: 17723929. Epub 2007/08/29. eng.

[12] T. O. Oshodi, "The impact of preoperative education on postoperative pain. Part 2," British Journal of Nursing, vol. 16, no. 13, pp. 790-797, 2007.

[13] E. Manias, "Pain and anxiety management in the postoperative gastro-surgical setting," Journal of Advanced Nursing, vol. 41, no. 6, pp. 585-594, 2003.

[14] J. L. Apfelbaum, C. Chen, S. S. Mehta, and A. T. J. Gan, "Postoperative pain experience: results from a national survey suggest postoperative pain continues to be undermanaged," Anesthesia \& Analgesia, vol. 97, no. 2, pp. 534-540, 2003.

[15] N. Vadivelu, S. Mitra, and D. Narayan, "Recent advances in postoperative pain management," The Yale Journal of Biology and Medicine, vol. 83, no. 1, pp. 11-25, 2010.

[16] G. P. Joshi and B. O. Ogunnaike, "Consequences of inadequate postoperative pain relief and chronic persistent postoperative pain," Anesthesiology Clinics of North America, vol. 23, no. 1, pp. 21-36, 2005.

[17] B. M. Boström, T. Ramberg, B. D. Davis, and B. Fridlund, "Survey of post-operative patients' pain management," Journal of Nursing Management, vol. 5, no. 6, pp. 341-349, 1997.

[18] S. E. Ward and D. B. Gordon, "Patient satisfaction and pain severity as outcomes in pain management: a longitudinal view of one setting's experience," Journal of Pain and Symptom Management, vol. 11, no. 4, pp. 242-251, 1996.

[19] J. A. McNeill, G. D. Sherwood, P. L. Starck, and C. J. Thompson, “Assessing clinical outcomes," Journal of Pain and Symptom Management, vol. 16, no. 1, pp. 29-40, 1998.
[20] J. Carlson, R. Youngblood, J. A. Dalton, W. Blau, and C. Lindley, "Is patient satisfaction a legitimate outcome of pain management?" Journal of Pain and Symptom Management, vol. 25, no. 3, pp. 264-275, 2003.

[21] T. Ahmed, N. Assefa, A. Demisie, and A. Kenay, "Levels of adult patients' satisfaction with nursing care in selected public hospitals in Ethiopia," International Journal of Health Sciences, vol. 8, no. 4, p. 371, 2014.

[22] T. G. Argago, K. W. Hajito, and S. B. Kitila, "Clients satisfaction with family planning services and associated factors among family planning users in Hossana town public health facilities, South Ethiopia: facility-based cross-sectional study," International Journal of Nursing and Midwifery, vol. 7, no. 5, pp. 74-83, 2015.

[23] S. B. Kitila, "Client satisfaction with abortion service and associated factors among clients visiting health facilities in Jimma town, Jimma, south west, Ethiopia," Quality in Primary Care, vol. 24, no. 2, 2016.

[24] M. Akhtari-Zavare, M. Y. Abdullah, S. T. S. Hassan, S. B. Said, and M. Kamali, "Patient satisfaction: evaluating nursing care for patients hospitalized with cancer in Tehran Teaching Hospitals, Iran," Global Journal of Health Science, vol. 2, no. 1, p. 117, 2010.

[25] T. Mindaye and B. Taye, "Patient's satisfaction with laboratory services at antiretroviral therapy clinics in public hospitals, Addis Ababa, Ethiopia," BMC Research Notes, vol. 5, no. 1, pp. 1-7, 2012.

[26] A. L. Comley and E. DeMeyer, "Assessing patient satisfaction with pain management through a continuous quality improvement effort," Journal of Pain and Symptom Management, vol. 21, no. 1, pp. 27-40, 2001.

[27] M. Schwenkglenks, H. J. Gerbershagen, R. S. Taylor et al., "Correlates of satisfaction with pain treatment in the acute postoperative period: results from the international PAIN OUT registry," Pain, vol. 155, no. 7, pp. 1401-1411, 2014.

[28] S. A. Stahmer, F. S. Shofer, A. Marino, S. Shepherd, and S. Abbuhl, "Do quantitative changes in pain intensity correlate with pain relief and satisfaction?" Academic Emergency Medicine, vol. 5, no. 9, pp. 851-857, 1998.

[29] M. W. Stomberg, K. Wickström, H. Joelsson, B. Sjöström, and H. Haljamäe, "Postoperative pain management on surgical wards-do quality assurance strategies result in long-term effects on staff member attitudes and clinical outcomes?" Pain Management Nursing, vol. 4, no. 1, pp. 11-22, 2003.

[30] T. J. Gan, A. S. Habib, T. E. Miller, W. White, and J. L. Apfelbaum, "Incidence, patient satisfaction, and perceptions of post-surgical pain: results from a US national survey," Current Medical Research and Opinion, vol. 30, no. 1, pp. 149-160, 2014.

[31] B. Subramanian, N. Shastri, L. Aziz et al., "Assist-patient satisfaction survey in postoperative pain management from Indian subcontinent," Journal of Anaesthesiology Clinical Pharmacology, vol. 33, no. 1, pp. 40-47, 2017, PubMed PMID: 28413271. Pubmed Central PMCID: 5374829. Epub 2017/04/ 18. eng.

[32] H. G. Masigati and K. S. Chilonga, "Postoperative pain management outcomes among adults treated at a tertiary hospital in Moshi, Tanzania," Tanzania Journal of Health Research, vol. 16, no. 1, 2014.

[33] P. S. Myles, D. L. Williams, M. Hendrata, H. Anderson, and A. M. Weeks, "Patient satisfaction after anaesthesia and surgery: results of a prospective survey of 10,811 patients," British Journal of Anaesthesia, vol. 84, no. 1, pp. 6-10, 2000. 
[34] A. Dihle, S. Helseth, U. E. Kongsgaard, S. M. Paul, and C. Miaskowski, "Using the American pain society's patient outcome questionnaire to evaluate the quality of postoperative pain management in a sample of Norwegian patients," The Journal of Pain, vol. 7, no. 4, pp. 272-280, 2006.

[35] D. B. Gordon, T. A. Pellino, C. Miaskowski et al., "A 10-year review of quality improvement monitoring in pain management: recommendations for standardized outcome measures," Pain Management Nursing, vol. 3, no. 4, pp. 116-130, 2002.

[36] T. E. Woldehaimanot, T. C. Eshetie, and M. W. Kerie, "Postoperative pain management among surgically treated patients in an Ethiopian hospital," PLoS One, vol. 9, no. 7, Article ID e102835, 2014.

[37] A. Borgeat, E. Tewes, N. Biasca, and C. Gerber, "Patientcontrolled interscalene analgesia with ropivacaine after major shoulder surgery: PCIA vs. PCA," British Journal of Anaesthesia, vol. 81, no. 4, pp. 603-605, 1998.

[38] C. Mann, Y. Pouzeratte, G. Boccara et al., "Comparison of intravenous or epidural patient-controlled analgesia in the elderly after major abdominal surgery," Anesthesiology, vol. 92 , no. 2 , p. $433,2000$.

[39] F. J. Singelyn and J.-M. A. Gouverneur, "Postoperative analgesia after total hip arthroplasty: IV PCA with morphine, patient-controlled epidural analgesia, or continuous "3-in-1" block?: a prospective evaluation by our acute pain service in more than 1,300 patients," Journal of Clinical Anesthesia, vol. 11, no. 7, pp. 550-554, 1999.

[40] J. A. De, J. Valia, A. Gil, and R. Bolinches, "Predictors of patient satisfaction with regional anesthesia," Regional Anesthesia, vol. 20, no. 6, pp. 498-505, 1995.

[41] S. Liu, R. L. Carpenter, and J. M. Neal, "Epidural anesthesia and analgesia," Anesthesiology, vol. 82, no. 6, pp. 1474-1506, 1995.

[42] C. Miaskowski, J. Crews, L. B. Ready, S. M. Paul, and B. Ginsberg, "Anesthesia-based pain services improve the quality of postoperative pain management," Pain, vol. 80, no. 1-2, pp. 23-29, 1999.

[43] R. N. Jamison, M. J. Ross, P. Hoopman et al., "Assessment of postoperative pain management: patient satisfaction and perceived helpfulness," The Clinical Journal of Pain, vol. 13, no. 3, pp. 229-236, 1997, PubMed PMID: 9303255. Epub 1997/09/26. eng.

[44] J. C. Ballantyne, D. B. Carr, T. C. Chalmers, K. B. G. Dear, I. F. Angelillo, and F. Mosteller, "Postoperative patientcontrolled analgesia: meta-analyses of initial randomized control trials," Journal of Clinical Anesthesia, vol. 5, no. 3, pp. 182-193, 1993. 